\title{
Images from the Haematologica Atlas of Hematologic Cytology: visceral leishmaniasis
}

\section{Rosangela Invernizzi ${ }^{1}$ and Antonello Malfitano ${ }^{2}$}

${ }^{1}$ University of Pavia and ${ }^{2} I R C C S$ Policlinico San Matteo Foundation, Pavia, Italy

E-mail: ROSANGELA INVERNIZZI - rosangela.invernizzi@unipv.it

doi:10.3324/haematol.2021.279161

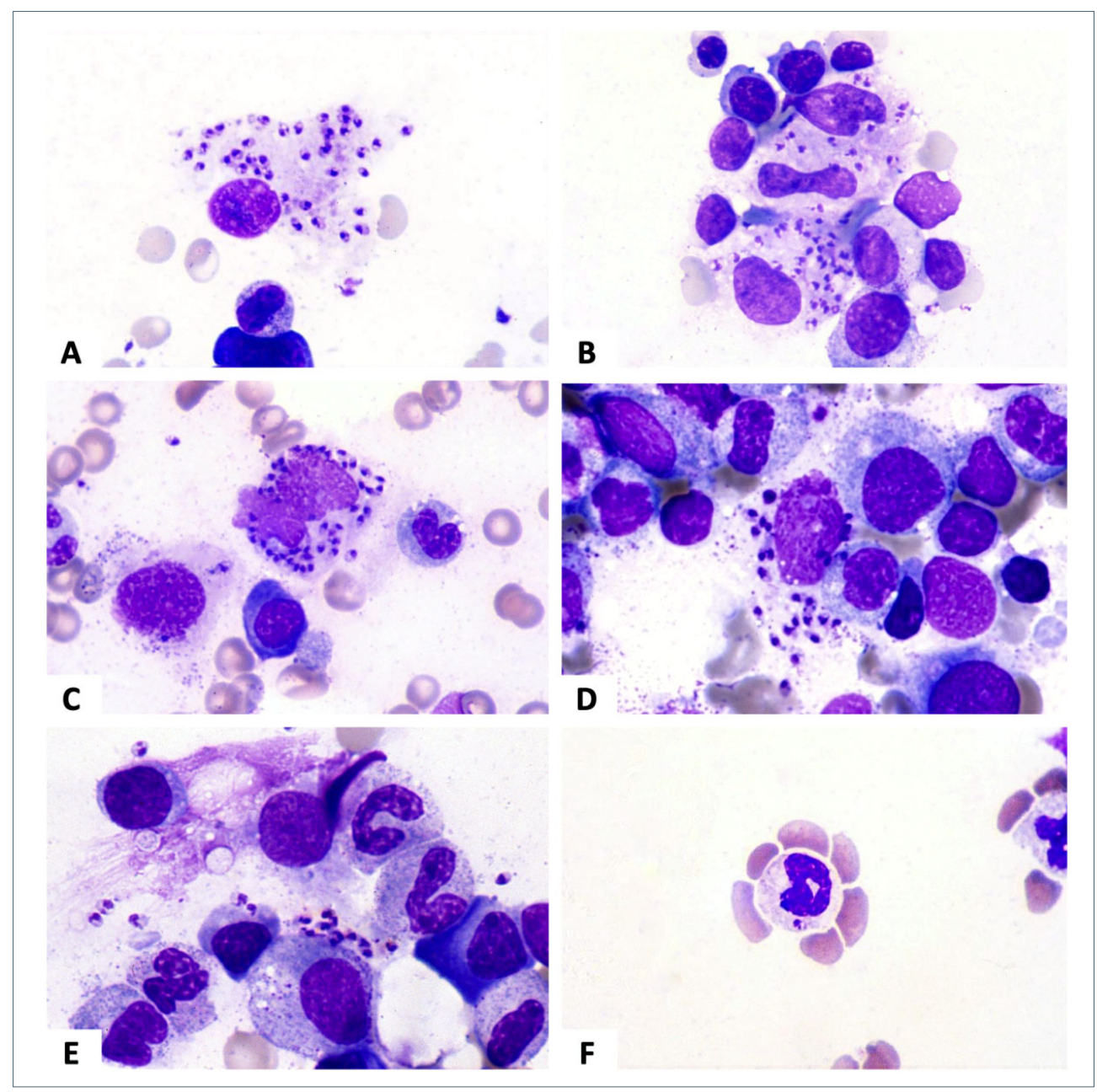

$\mathrm{B}$ one marrow smears remain the diagnostic gold standard for visceral leishmaniasis, although Donovan's bodies, the identifying marker of the disease, may also be found in lymph nodes as well as in spleen fine-needle aspirate smears. These bodies are the asexual form of the parasite, the so-called amastigotes. They are oval, measure 1-5 $\mu \mathrm{m}$ long by 1-2 $\mu \mathrm{m}$ wide, and show a round nucleus and a bar-shaped inclusion, the kinetoplast, which is the remnant of the flagellum of the promastigote. Amastigotes of Leishmania donovani may be numerous inside bone marrow macrophages (Figure A-D) or extracellularly as macrophages can be broken during preparation of the smear (Figure E). They may also be observed in the peripheral blood within the cytoplasm of granulocytes, particularly after centrifugation and concentration of white blood cells (Figure F). ${ }^{1}$

\section{Disclosures}

No conflicts of interest to disclose.

\section{Contributions}

Both authors contributed.

\section{Reference}

1. Malfitano A, Invernizzi R. Parasitic and fungal diseases. Haematologica. 2020;105(Suppl 1):29-39. 